ORIGINAL ARTICLE

\title{
Growth on stimulant medication; clarifying the confusion: a review
}

\section{A Poulton}

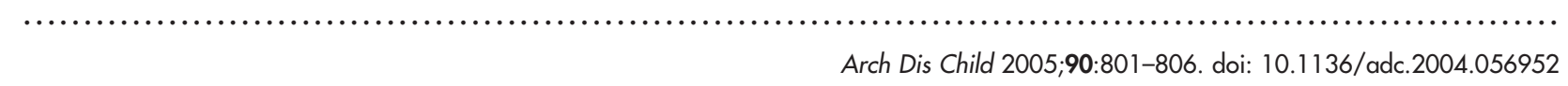

\begin{abstract}
Aims: To get an overview of the studies of growth in height in children with attention deficit hyperactivity disorder (ADHD) treated with stimulant medication, to establish the consistencies and to try to resolve the discrepancies.

Methods: Twenty nine studies were reviewed following a Medline search: 22 related to children, six to late adolescents or adults, and one to children and adults.

Results: Children: Eleven studies gave results consistent with height attenuation on stimulant medication: eight were longitudinal, one was cross-sectional, and two showed growth rebound on ceasing medication. Studies with negative findings were inadequately powered $(n=3)$, lacked controls or statistical analysis $(n=3)$, measured height velocity without reference to treatment duration $(n=2)$, or used inappropriate growth parameters $(n=1)$, controls $(n=1)$, or normative data $(n=1)$. Late adolescents/adults treated with stimulant medication in childhood: Two studies associated childhood gastrointestinal side effects with attenuated late adolescent or adult height; all six cross-sectional studies had negative findings. The methodologies varied widely but there was some consistency in the degree of attenuation shown in studies with positive findings. The most sensitive methods analysed the changes in z-scores (standard deviation scores) or calculated the height deficits from paired measurements taken before and after an initial period of treatment with stimulant medication. The height deficit amounted to approximately $1 \mathrm{~cm} /$ year during the first 1-3 years of treatment.

Conclusions: Further research is needed into the causal mechanisms, the rate of physical maturation, and the long term implications for final stature.
\end{abstract}

Correspondence to: Dr A Poulton, Western Clinical School, Nepean Campus, The University of Sydney, Australia; sally_poulton@iinet.net.au

Accepted 22 March 2005
S timulant medication was first suspected to have an adverse effect on growth in height in children with ADHD by a school nurse Evelyn Barr. ${ }^{1}$ Following her observations, Safer and Allen published studies in the 1970s showing early weight loss and growth in height that remained slower than controls for the first three years of treatment. ${ }^{1}$ Rebound growth on ceasing medication was also shown. ${ }^{2}$ Safer and Allen's work was followed by a spate of studies, some replicating their results and others showing little effect on growth in height, although weight loss on starting stimulant medication has been a usual finding. As a result of ongoing discrepancies in the published literature, knowledge in this important area has advanced very little over the past 30 years and this topic remains one of confusion and controversy.

The purpose of this paper was to get an overview of the studies of growth in height in children with ADHD, to establish the consistencies, and to try to resolve the discrepancies. The effect of stimulant medication on growth in weight was not examined because it is more widely accepted that stimulant medication may be associated with transient weight loss, and because fluctuations in weight are often regarded as less serious as weight can be regained later.

\section{METHODS}

A Medline search up to September 2004 was conducted using the keyword "growth" combined with "ADHD", "methylphenidate", or "dexamphetamine". Reference lists of the articles were also screened. Studies reviewed were all cohort studies of children with ADHD treated with methylphenidate or dexamphetamine, or of adults treated as children. Studies were excluded if they had less than 10 subjects or lacked sufficient details for some analysis of the methodology. Data on pemoline were not included as this is used less frequently due to the risk of adverse effects.

Studies were classified, analysed, and evaluated according to the study design and whether the subjects were children or late adolescents/adults.

\section{RESULTS}

Twenty nine studies met the selection criteria. There were 22 studies of children, six studies of adults or adolescents close to their adult height, and one study that included both children and adults. Some studies have been published in two stages and therefore have two separate references. Seven studies related only to boys, one only to girls, and the remainder included both boys and girls or only specified "children". The adult studies consisted either exclusively or predominantly of men.

\section{Studies in children}

Table 1 summarises 21 studies in children classified by the study design. Nine of these gave results consistent with statistically significant attenuation of growth in height on stimulants and 12 had negative findings. In addition to these there were studies by Safer and colleagues ${ }^{2}$ and Klein and colleagues ${ }^{26}$ showing rebound growth on ceasing medication, implying that on medication growth had been attenuated.

\section{Dose of stimulant medication}

The dose of methylphenidate or methylphenidate equivalent (calculated by doubling the dose of dexamphetamine) for the nine studies in table $\mathrm{l}$ showing statistically significant attenuation ranged from 21.6 to $42 \mathrm{mg}$ (median $31.4 \mathrm{mg}$ ). For the 12 studies with negative findings, the range for the nine which specified mean dosage was 18.4-34 mg (median $23.9 \mathrm{mg}$ ). Studies using lower doses of methylphenidate ${ }^{19}$ 
Table 1 Summary of the methodology and results of 21 stimulant growth studies in children

\begin{tabular}{|c|c|c|c|c|c|c|}
\hline & $\begin{array}{l}\text { Treatment } \\
\text { (mg/day) }\end{array}$ & $\mathrm{n}$ & $\begin{array}{l}\Delta \text { Height } \\
\text { centile }\end{array}$ & $\Delta$ Height z-score & $\begin{array}{l}\Delta \text { Calculated } \\
\text { adult height }\end{array}$ & Height deficit $(\mathrm{cm})$ \\
\hline \multirow[t]{3}{*}{ Safer and Allen, 1973' } & $\mathrm{Mph}>20$ & 10 & $\begin{array}{l}p<0.05 \\
(3 \text { years })\end{array}$ & & & $1.0 \mathrm{~cm} /$ year $^{*}$ \\
\hline & $M p h \leqslant 20$ & 10 & NS & & & \\
\hline & Dex 12.5 & 29 & $\begin{array}{l}p<0.005 \\
(2.9 \text { years) }\end{array}$ & & & $1.5 \mathrm{~cm} /$ year* \\
\hline Kalachnik ef al, $1982^{3}$ & Mph 18.4 & 23 boys & & & NS & \\
\hline Spencer et al, $1992^{4}$ & Mph 31.4 & 29 & NS & $p=0.023$ (1.2 years) & & $\begin{array}{l}1.5 \text { at } 1.2 \text { years } \\
p=0.035\end{array}$ \\
\hline Lisska and Rivkees, $2003^{5}$ & Mph 21.6 & 84 & & $\begin{array}{l}\text { Boys } p=0.01 \text { ( } 3 \text { and } \\
4 \text { years) Girls } p=0.05 \\
\text { ( } 3 \text { years) }\end{array}$ & & $\begin{array}{l}\text { Boys } 3-4 \text { at } 3 \text { years } \\
\text { Girls } 3-4 \text { at } 3 \text { years }\end{array}$ \\
\hline $\begin{array}{l}\text { MTA Cooperative Group } \\
2001,{ }^{6} 2004^{7}\end{array}$ & Mph 34.4 & 222 & & & & $\begin{array}{l}1.05 \text { at } 14 \text { months } \\
p<0.0011 .92 \text { at } \\
24 \text { months } p<0.001\end{array}$ \\
\hline
\end{tabular}

Design: longitudinal from onset of treatment with stimulant

Control: normative data

\begin{tabular}{|c|c|c|c|c|c|}
\hline & Treatment (mg/day) & $\mathbf{n}$ & $\Delta$ Height centile & $\Delta$ Height z-score & Height deficit $(\mathrm{cm})$ \\
\hline Gross $1976^{8}$ & Mph 34, Dex 16.5 & 84 & NS & & \\
\hline Millichap, $1978^{\circ}$ & Mph 10-20 & 36 boys & NS & & \\
\hline Satterfield et al, $1979^{10}$ & Mph 24.2 & 72 boys & & & $\begin{array}{l}1.03 \text { at } 1 \text { year } \\
\mathrm{p}<0.0010 .1 \\
\text { at } 2 \text { years NS }\end{array}$ \\
\hline Kaffman et al, 1979"1 & Mph 20, Dex 20 & 50 & NS & & \\
\hline Greenhill et al, $1981^{12}$ & Dex 21 & 13 boys & $\begin{array}{l}p<0.025 \\
(1 \text { year) }\end{array}$ & & $\begin{array}{l}1.8 \text { at } 1 \text { year } \\
p<0.005\end{array}$ \\
\hline $\begin{array}{l}\text { Mattes and Gittelman, } \\
1983^{13}\end{array}$ & Mph 41.3 & 56 & $\begin{array}{l}p<0.001 \\
(2,3,4 \text { years })\end{array}$ & & 3.3 at 4 years \\
\hline Gadow et al, $1999^{14}$ & Mph 30 & 34 & & & 0.67 at 2 years NS \\
\hline Poulton and Cowell, $2003^{15}$ & Mph 27, Dex 13.7 & 51 & & $\begin{array}{l}p<0.001 \\
(1 / 2,11 / 2 \text { years })\end{array}$ & $\begin{array}{l}0.64 \text { at } 1 / 2 \text { year } \\
p<0.0012 .33 \text { at } \\
21 / 2 \text { years } p<0.01\end{array}$ \\
\hline
\end{tabular}

Design: longitudinal from onset of treatment with stimulant

Control: partially treated children

\begin{tabular}{|c|c|c|c|c|c|c|}
\hline & Treatment (mg/day) & $\mathbf{n}$ & $\Delta$ Height centile & & & \\
\hline Quinn and Rapoport $1975^{16}$ & Mph 20.6 & 23 boys & NS & & & \\
\hline \multicolumn{7}{|c|}{$\begin{array}{l}\text { Design: longitudinal from onset of treatment with stimulant } \\
\text { Control: none }\end{array}$} \\
\hline & Treatment (mg/day) & $\mathbf{n}$ & \multicolumn{4}{|l|}{ Height velocity } \\
\hline Sund and Zeiner $2002^{17}$ & Mph 23.9 Dex 11.9 & 91 boys & \multicolumn{4}{|l|}{ NS } \\
\hline \multicolumn{7}{|c|}{$\begin{array}{l}\text { Design: longitudinal study of children changing formulation } \\
\text { Control: none }\end{array}$} \\
\hline & $\begin{array}{l}\text { Duration of treatment } \\
\text { prior to study }\end{array}$ & Treatment (mg/day) & $\mathbf{n}$ & \multicolumn{3}{|l|}{$\begin{array}{l}\text { Change in average } \\
\text { height of cohort }\end{array}$} \\
\hline Wilens et al, $2003^{18}$ & $\begin{array}{l}\text { Not stated (most were } \\
\text { treated) }\end{array}$ & Mph 18-54 & $\begin{array}{l}407 \text { at start } \\
229 \text { at } 1 \text { year }\end{array}$ & \multicolumn{3}{|l|}{ NS } \\
\hline \multicolumn{7}{|c|}{$\begin{array}{l}\text { Design: cross sectional } \\
\text { Control: untreated children with ADHD or normal children }\end{array}$} \\
\hline & $\begin{array}{l}\text { Duration of treatment } \\
\text { prior to study }\end{array}$ & Treatment (mg/day) & $\mathbf{n}$ & Height z-score & \multicolumn{2}{|l|}{ Height velocity } \\
\hline McNutt et al, $1976,^{19} 1977^{20}$ & 9-47 months mean 30.3 & Mph 19.8 & 20 & & \multirow{5}{*}{\multicolumn{2}{|c|}{ NS }} \\
\hline Spencer et al, 1996, ${ }^{21} 1998^{22}$ & $\begin{array}{l}\text { Average } 4 \text { years } \\
\text { follow up }\end{array}$ & $\begin{array}{l}\text { Any treatment } \\
\text { ever }\end{array}$ & 110 boys & $p=0.03$ & & \\
\hline \multirow{3}{*}{ Biederman et al, $2003^{23}$} & & Mph 38† & 53 boys & NS & & \\
\hline & Not stated & Any treatment ever & 87 girls & NS & & \\
\hline & & Mph $28 \dagger$ & 73 girls & NS & & \\
\hline \multicolumn{7}{|l|}{$\begin{array}{l}\text { Design: cross sectional } \\
\text { Control: normative data }\end{array}$} \\
\hline & $\begin{array}{l}\text { Duration of treatment } \\
\text { prior to study }\end{array}$ & $\begin{array}{l}\text { Treatment } \\
\text { (mg/day) }\end{array}$ & $\mathbf{n}$ & \multicolumn{2}{|l|}{ Height centile } & Height velocity \\
\hline Millichap and Millichap, $1975^{24}$ & $\begin{array}{l}1-5 \text { years } \\
\text { mean } 2 \frac{1}{2} \text { years }\end{array}$ & Mph 10-40 & 50 & \multicolumn{3}{|l|}{ NS } \\
\hline Vincent et al, $1990^{25}$ & $1 / 2-7$ years & Mph 34 & 31 & & & NS \\
\hline
\end{tabular}

n, number of subjects; Mph, methylphenidate daily dose; Dex, dexamphetamine/amphetamine daily dose; NS, method used but did not show statistically significant evidence of attenuated growth.

*The height deficits in Safer and Allen's studies represent averaged annual deficits from children in their first, second, or third year of treatment

†Average dose of methylphenidate or equivalent in subgroup of children who received a stimulant in past 2 years. 
(20 mg/day or less) did not show a significant effect on growth in height. The studies that analysed dexamphetamine $^{112}$ showed more attenuation in the first year than studies that combined both stimulants during analysis or used only methylphenidate.

\section{Growth parameters}

There was considerable variation in the parameters used for analysing growth, making it difficult to compare the results of the different studies. The most frequently used method that consistently indicated attenuated growth in height and was possible to compare between studies was the height deficit. A height deficit of $3 \mathrm{~cm}$ means that the child is $3 \mathrm{~cm}$ shorter than he would be if he had continued to grow at the expected rate. The height deficit can be calculated from the change in centile, the change in z-score, or in a clinical setting it can be estimated directly from the growth chart. The early study by Spencer and colleagues ${ }^{4}$ showed that the change in height $\mathrm{z}$-score and the height deficit are more sensitive parameters for monitoring growth than the change in height centile, a method which distorts the data due to the non-linear relation between change in height and change in centile.

\section{Longitudinal studies}

The most sensitive design was the longitudinal study analysing paired observations taken before and after an initial period of treatment with stimulant medication. Table 1 indicates that half $(8 / 16)$ of the studies with this methodology showed attenuated growth on stimulants by at least one method, most reliably the change in height z-score (significant in 3/3). The height deficit reached statistical significance in 5 of the 6 studies with sufficient detail for a $\mathrm{p}$ value.

The study with the most scientifically rigorous methodology was the MTA study ${ }^{6}{ }^{7}$ in which children with ADHD were allocated at random into different treatment groups. The children who received stimulant medication had an average height deficit of $0.9 \mathrm{~cm} /$ year during the first 14 months and $1.04 \mathrm{~cm} /$ year from 14-24 months when compared with children whose treatment was non-pharmacological. Four other studies compared treated children with control groups consisting either of untreated children with $\mathrm{ADHD}^{13}$ or normal children. ${ }^{3-5}$ Three of the four studies with this design showed height attenuation by at least one method in at least one treatment group. The fourth, by Kalachnik and colleagues, ${ }^{3}$ calculated the projected adult stature using the RocheWainer-Thissen formula and analysed changes in this projection after $1-3$ years of treatment. The formula takes into consideration mid-parental stature, and child's weight and recumbent length, with regression coefficients for each of these which change with every six month age bracket. As a method for monitoring growth, this would not only add variability to the data due to the changing coefficients, but would also systematically undervalue attenuation of growth in height occurring in the presence of weight loss or poor weight gain. Both of these problems would increase the likelihood of failing to detect a significant effect (type II error).

Eight longitudinal studies ${ }^{8-15}$ used normative data as the control without confirming its validity for normal children. Three of these $\mathrm{e}^{12} 1315$ showed height attenuation of a magnitude reasonably consistent with the studies that used untreated children as controls, suggesting that the height velocities of the normative data may have been appropriate. By contrast the studies by Gross ${ }^{8}$ and Satterfield and colleagues $^{10}$ used the Iowa Growth Tables, ${ }^{27}$ published in 1941, which have an average height velocity for boys aged 8-11 years that is $0.7 \mathrm{~cm} /$ year less than the 1976 National Centre for Health Statistics charts. ${ }^{28}$ This may explain the progressive gain in height centiles observed by Gross in all treatment groups and resolution of the height deficit in the second year of treatment in the study by Satterfield et al. The reason for the smaller height deficit of $0.67 \mathrm{~cm}$ in two years in the study by Gadow and colleagues ${ }^{14}$ is unclear. However, the statistical analysis used an unpaired $t$ test instead of the more powerful paired $t$ test, effectively reducing the power of this longitudinal study to that of a cross sectional study that compares unrelated groups. The study by Kaffman and colleagues $^{11}$ lacked rigorous analysis, only observing the numbers crossing certain centile lines on treatment. The study by Quinn and Rapoport ${ }^{16}$ compared treated children with controls who had received treatment for up to four months out of a 12 month study period. The unsupported assumption that any effect of stimulant medication on growth in the first four months would have normalised, combined with the small numbers and analysis using change in centile may explain the negative findings. The studies by Sund and Zeiner ${ }^{17}$ and Wilens and colleagues ${ }^{18}$ lacked any kind of control group for comparison. The study by Wilens et al had a $44 \%$ drop out rate which renders meaningless any comparison of the average height of the cohort before and after 12 months of treatment.

\section{Cross sectional studies}

Cross sectional studies lack the statistical power associated with comparing paired measurements of the same subjects before and after a period of treatment. Table 2 shows the estimated number in each group (subjects and controls) required for a cross sectional study to detect a height deficit of a magnitude comparable to those shown in table 1. This indicates that the study by Millichap and Millichap ${ }^{24}$ and the cross sectional analysis by Gadow and colleagues ${ }^{14}$ were inadequately powered, and the study by Biederman and colleagues $^{23}$ had adequate power to detect a treatment effect only if the subjects had been treated for three years or more, information lacking in the published report. The study by Spencer and colleagues ${ }^{21} 22$ was the only cross sectional study to show a difference in height z-score between children with ADHD and normal children, and was the only adequately powered cross sectional study. This study is difficult to interpret due to the lack of information on treatment

Table 2 Power calculations: required sample size for cross sectional studies $(80 \%$ confidence for 0.05 two sided significance)

\begin{tabular}{llll}
\hline $\begin{array}{l}\text { Duration of } \\
\text { treatment }\end{array}$ & $\begin{array}{l}\text { Anticipated height } \\
\text { deficit }\end{array}$ & $\begin{array}{l}\text { Anticipated change } \\
\text { in height } \mathbf{z} \text {-score }\end{array}$ & $\begin{array}{l}\text { Required number of individuals } \\
\text { per group }(\mathbf{n})\end{array}$ \\
\hline 1 year & $1.0 \mathrm{~cm}$ & -0.17 & $554-797^{*}$ \\
2 years & $2.0 \mathrm{~cm}$ & -0.33 & $147-212^{*}$ \\
3 years or more & $3.0 \mathrm{~cm}$ & -0.5 & $64-92^{*}$ \\
\hline
\end{tabular}

*Calculated using the formula: $n=16 / f^{2}$; where $n$, number in each group, $f$, expected change expressed as a fraction of the standard deviation. The standard deviation for height was taken as $6.0 \mathrm{~cm}$ and the cohort standard deviation in $z$-scores was estimated as 1.0 to 1.2 . 
Table 3 Studies of late adolescent and adult height of individuals treated with stimulant medication in childhood

\begin{tabular}{|c|c|c|c|c|c|c|}
\hline \multicolumn{7}{|l|}{ Design: cross sectional } \\
\hline & Methylphenidate (mg/day) & Duration & n & Height $(\mathrm{cm})$ & Height z-score & Controls \\
\hline Beck et al, $1972^{29}$ & $\begin{array}{l}\text { Not stated } \\
\text { No statistical analysis }\end{array}$ & Not stated & 30 & NS & & $\begin{array}{l}\text { Normal } \\
\text { adolescents }\end{array}$ \\
\hline Hechtman et al, $1984^{30}$ & $\begin{array}{l}20-50 \\
\text { No details given of analysis }\end{array}$ & $\geqslant 3$ years & 20 & NS & & $\begin{array}{l}\text { ADHD adults } \\
\text { never treated } \\
\text { Normal adults }\end{array}$ \\
\hline Klein and Mannuzza, $1988^{31}$ & 45 & 2.24 years & 61 boys & NS & & $\begin{array}{l}\text { Normal } \\
\text { adolescents }\end{array}$ \\
\hline Spencer et al, 1996, ${ }^{21} 1998^{22}$ & $\begin{array}{l}38^{*} \\
\text { Uncertain proportion treated with stimulant }\end{array}$ & 4 years follow up & $25+$ men & & NS & Normal adults \\
\hline Kramer et al, $2000^{32}$ & 31.2 & 3 years & 97 men & NS & & $\begin{array}{l}\text { Adult family } \\
\text { members } \\
\text { Normal adults }\end{array}$ \\
\hline Oettinger et al, $1977^{33}$ & Dexamphetamine $16 \mathrm{mg} /$ day & $\begin{array}{l}4.5-16.2 \text { years } \\
\text { follow up }\end{array}$ & 25 men & NS & & $\begin{array}{l}\text { Normative } \\
\text { data }\end{array}$ \\
\hline \multicolumn{7}{|c|}{ Design: longitudinal using multiple regression analysis } \\
\hline $\begin{array}{l}\text { Loney et al, } 1981^{34} \\
\text { Kramer et al, } 2000^{32}\end{array}$ & $\begin{array}{l}7 \% \text { of variability of adolescent height predi } \\
4.4 \% \text { of variability of adult height predicted }\end{array}$ & y treatment si & & & & \\
\hline
\end{tabular}

n, number of subjects; Duration, duration of treatment: average or range; NS, method used but did not show statistically significant evidence of attenuated growth. *Average dose of methylphenidate or equivalent.

†Subgroup of individuals aged $>18$ years in a study principally of children.

duration within the different treatment subgroups. Two studies analysed height velocity ${ }^{19} 25$ without taking into consideration that this could vary with the duration of treatment.

\section{Studies of late adolescent and adult height of individuals treated in childhood}

There were five cross sectional studies looking at late adolescent or adult height ${ }^{29-33}$ and one looking at both children and adults. ${ }^{21}{ }^{22}$ None showed any significant difference between those treated with stimulants in childhood and controls (table 3). One possible explanation is that the numbers may have been insufficient. Tables 2 and 3 suggest that five of the six studies may be inadequately powered, although the calculations used for table 2 may not be applicable to data on adult height. Another possibility is that there may have been catch up growth during puberty. The adults were still on stimulant medication in only one study,,$^{33}$ and in view of the observation that children ceasing treatment with stimulant medication may have accelerated growth, ${ }^{26}$ it is possible that some who ceased medication while still growing might have caught up.

Two studies ${ }^{32}{ }^{34}$ used a retrospective longitudinal design, and by multiple regression analysis showed that $4.4 \%$ and $7 \%$ respectively of the variation in adult height and adolescent height was predictable from treatment side effects of appetite suppression, nausea, and vomiting. In the study by Kramer and colleagues ${ }^{32}$ this amounted to a deficit of $6.6 \mathrm{~cm}$ when compared to individuals without these side effects.

\section{DISCUSSION}

\section{Principle findings}

Many of the studies reviewed were of poor quality and would have been excluded had rigorous selection criteria been applied. There was clear evidence of an association between treatment with stimulant medication and attenuated growth in height in the better quality studies. ${ }^{14-7} 121315$

The most reliable method for showing attenuated growth was the longitudinal study analysing the changes in z-scores or calculating the height deficits from paired measurements taken before and after an initial period of treatment with stimulant medication. In studies that had untreated control groups the investigators did not have to make the assumption that the normative data was appropriate.
Cross sectional studies in children have tended to be under-powered, therefore their negative findings can be discounted.

While it might be desirable to combine the results of the studies in table 1 to get an accurate height deficit for the first, second, and third year of treatment, the time periods are too variable and there is insufficient data for this to be possible, although an average height deficit of approximately $1 \mathrm{~cm} /$ year during the first 1-3 years of treatment would appear to be a reasonable estimate. Further studies are needed to define the annual height deficits more precisely, relating these to the dose of stimulant medication. There is also a need for more long term studies with continuous follow up defining the growth pattern through adolescence until adult height is reached.

The effect of stimulant medication on growth in height may be dose dependent, attenuation being shown less frequently at doses not exceeding $20 \mathrm{mg}$ /day of methylphenidate. Dexamphetamine may be associated with more attenuation than methylphenidate.

The finding that side effects of medication may be associated with a permanent adverse effect on growth ${ }^{32}{ }^{34}$ is a cause of concern. This needs further study, looking at the early velocities for height and weight to find out if these are more attenuated in duration or degree in children with gastrointestinal side effects.

\section{Strengths and weaknesses}

This is the largest and most detailed review to date of the studies of growth in children with ADHD treated with dexamphetamine or methylphenidate. The inclusion criteria were broad as the intention was to include, rather than to exclude, the studies with poorer quality methodology. Once a study has been published in a reputable journal there is a risk that readers will assume the conclusions are correct without checking that they are supported by the data, that the methodology is appropriate, and that the study is adequately powered. It is important for the scientific integrity of the medical literature as a whole that the poorer studies do not stand without published critique.

Another strength of this review is in the classification of the studies according to their overall design. The results of each study were then examined in the context of the 


\section{What is already known on this topic}

- It has previously been shown that stimulant medication may be associated with weight loss and attenuated growth in height, and correlations between these effects have been shown

- However, a substantial number of studies have not shown any significant effect of stimulant medication on growth in height, leading to this being a controversial issue

- Most studies of children starting stimulant medication have shown initial weight loss, and it is generally accepted that weight loss is an effect of stimulant medication

methodology, reinterpreting the findings where appropriate rather than simply summarising the authors' conclusions.

It was not possible to divide the studies in children into pre-adolescents and adolescents because the details were lacking, although there may be an important distinction between the effect of stimulants before and after the onset of puberty.

Some details such as the accuracy of the measurements and the appropriateness of the normative data for comparison in the individual studies have not been fully addressed.

\section{Relation between attenuated growth in height and weight on stimulant medication and possible mechanisms}

Studies comparing changes in height and weight have found reductions in centile scores in the first $1-2$ years, with weight affected more than height. ${ }^{141213}$ In the two studies of longer duration the weight centile stabilised but the height centile continued its decline for the third and fourth year. ${ }^{1}{ }^{13}$ Safer and Allen $^{35}$ found a significant correlation between the changes in centiles for height and weight, not replicated in some of the later studies. ${ }^{4}$ Poulton and Cowell ${ }^{15}$ found ratios of changes in z-scores of weight to height of 4.3, 2.2, 1.95, and 2.1 at $6,18,30$, and 42 months respectively, the ratios stabilising but the $\mathrm{z}$-scores continuing to decline into the third year. The correlation between the cumulative changes in z-scores for height and weight became closer with time: $r=0.39,0.47,0.88$, and 0.97 at $6,18,30$, and 42 months respectively. The closeness of this correlation would appear to indicate that stimulant medication affects both height and weight by a single mechanism.

Poulton and Cowell ${ }^{15}$ analysed the height velocity at different durations of treatment and found that it was slowest in the first six months, coinciding with the period with the fastest reduction in weight $\mathrm{z}$-score. It may be hypothesised that as soon as the child goes into negative energy balance, growth in height is switched off to basal levels. The weight stabilises and then starts to increase, resuming a normal or near normal rate of weight gain after 1-2 years but at a lower centile or z-score. The height takes longer to adjust to this new equilibrium, normal velocities being attained after $2 \frac{1}{2}-3 \frac{1}{2}$ years. The change in height $\mathrm{z}$ score after 30 months of treatment may be predicted from the change in weight $\mathrm{z}$-score after six months using the formula $y=0.47 x-0.17$ where $y$ is the change in height $z$ score after 30 months and $\mathrm{x}$ is the change in weight $\mathrm{z}$-score after six months of treatment (Pearson's correlation coefficient $\mathrm{r}=0.76, \mathrm{p}=0.0017$ using paired $t$ test) ${ }^{36}$

On cessation of medication one study has shown catch up growth in weight and height occurring together over a three month period ${ }^{2}$ and one study has shown initial catch up

\section{What this study adds}

- This study is an extensive analysis of the available literature on growth in height in children on stimulant medication

- The results of previous studies have been evaluated and shown to be broadly consistent with a pattern of initial weight loss on starting stimulant medication, and resumption of weight gain, but at a lower weight centile or z-score, and attenuation of the height velocity by approximately $1 \mathrm{~cm} /$ year for the first three years of treatment

- A hypothesis is presented that weight gain drives growth in height, with height taking longer to adjust to a new equilibrium on stimulant medication. Some original data are presented in support of this. From the limited data on catch up growth on ceasing stimulant medication it is hypothesised that a similar mechanism applies

- This study offers explanations for many of the apparently conflicting findings of previous studies

growth in weight without any catch up growth in height. ${ }^{26}$ This could be explained if weight gain drives growth in height after a variable lag phase, perhaps while body energy stores are being replenished. The MTA study ${ }^{6}$ did not show any catch up growth in children who came off their medication after the first 14 months: the growth rate for weight normalised in the subsequent 10 months and the height velocity remained attenuated. Children were classified as unmedicated from 10 to 24 months if they had ceased stimulant medication for at least one month at the time of the 24 month follow up. Some might therefore have received stimulant medication for a substantial part of this period, obscuring the effect of catch up growth in others.

It is possible that stimulant medication may activate mechanisms adapted for surviving acute starvation, conserving energy stores by restricting growth in height. No mediators for the effect of stimulant medication on growth have yet been identified but a starting point for research might be to look at hormones that may regulate the appetite.

It remains unclear whether the reduction in the height velocity represents a delay in physical maturation or whether children continue to mature physically at the normal rate. Longer term studies are needed, looking at the rate of progression of the bone age and pubertal development in children on stimulants.

\section{Conclusions}

The most noticeable point that comes out of this review is the plethora of studies, some from tertiary centres, that have failed to detect an adverse effect of stimulant medication on growth in height in children with ADHD, an effect that can readily be shown in a community setting using the most basic of equipment. Studies vary widely in their methodology and this review has shown that many do not stand up to rigorous analysis.

The reasonable degree of consistency in the height deficit in studies with positive findings makes it implausible that this should be due to artefact. Doctors treating children with stimulant medication should therefore anticipate a reduction in the height velocity, and growth should be closely monitored. It would appear that most children achieve a satisfactory adult height, but there may be an important subgroup whose growth is permanently attenuated. 
The confusion resulting from the discrepancies in the literature has diverted attention from the important question that follows on from this: what is the significance of the period of poor growth that many children experience when starting stimulant medication? There seems to be an assumption among clinicians that for most children the effect on growth is clinically unimportant, particularly when balanced against a favourable response in controlling the symptoms of ADHD. This may turn out to be correct, but further research is needed to evaluate this assumption. The effect of stimulant medication on growth needs to be studied prospectively and over longer time periods looking into the causal mechanisms, the rate of physical maturation, and the long term implications for final stature.

\section{ACKNOWLEDGEMENTS}

I acknowledge Dr P Oakeshott for comments on the manuscript.

Competing interests: none

\section{REFERENCES}

1 Safer DJ, Allen RP. Factors influencing the suppressant effects of two stimulant drugs on the growth of hyperactive children. Pediatrics 1973;51:660-7.

2 Safer DJ, Allen RP, Barr E. Growth rebound after termination of stimulant drugs. J Pediatr 1975;86:113-16.

3 Kalachnik JE, Sprague RL, Sleator EK, et al. Effect of methylphenidate hydrochloride on stature of hyperactive children. Dev Med Child Neurol 1982;24:586-95.

4 Spencer T, Biederman J, Wright V, et al. Growth deficits in children treated with desipramine: a controlled study. J Am Acad Child Adolesc Psychiatry 1992;31:235-43.

5 Lisska MC, Rivkees SA. Daily methylphenidate use slows the growth of children: a community based study. J Pediatr Endocrinol Metab 2003;16:711-18

6 Vitiello B, Severe JB, Greenhill LL, et al. Methylphenidate dosage for children with ADHD over time under controlled conditions: lessons from the MTA. J Am Acad Child Adolesc Psychiatry 2001;40:188-96.

7 MTA Cooperative Group. National Institute of Mental Health Multimodal Treatment Study of ADHD Follow-up: changes in effectiveness and growth after the end of treatment. Pediatrics 2004;113:762-9.

8 Gross MD. Growth of hyperkinetic children taking methylphenidate, dextroamphetamine, or imipramine/desipramine. Pediatrics 1976;58:423-31.

9 Millichap G. Growth of hyperactive children treated with methylphenidate. Journal of Learning Disabilities 1978;11:40-3.

10 Satterfield JH, Cantwell DP, Schell A, et al. Growth of hyperactive children treated with methylphenidate. Arch Gen Psychiatry 1979;36:212-17.

11 Kaffman M, Sher A, Bar-Sinai N. MBD Children-variability in developmental patterns or growth inhibitory effect of stimulants? The Israel Annals of Psychiatry and Related Disciplines 1979;17:58-66.

12 Greenhill LL, Puig-Antich J, Chambers W, et al. Growth hormone, prolactin, and growth responses in hyperkinetic males treated with D-amphetamine. J Am Acad Child Psychiatry 1981;20:84-103.

13 Mattes JA, Gittelman R. Growth of hyperactive children on maintenance regimen of methylphenidate. Arch Gen Psychiatry 1983;40:317-21.
14 Gadow KD, Sverd J, Sprafkin J, et al. Long-term methylphenidate therapy in children with comorbid attention-deficit hyperactivity disorder and chronic multiple tic disorder. Arch Gen Psychiatry 1999;56:330-6.

15 Poulton A, Cowell CT. Slowing of growth in height and weight on stimulants: a characteristic pattern. J Paediatr Child Health 2003;39:180-5.

16 Quinn PO, Rapoport JL. One year follow up of hyperactive boys treated with imipramine or methylphenidate. Am J Psychiatry 1975;132:241-5.

17 Sund AM, Zeiner P. Does extended medication with amphetamine or methylphenidate reduce growth in hyperactive children? Nordic J Psychiatry 2002;56:53-7.

18 Wilens T, Pelham W, Stein M, et al. ADHD treatment with once daily OROS methylphenidate: interim 12 month results from a long term open label study. J Am Acad Child Adolesc Psychiatry 2003:42:424-33.

19 McNutt BA, Ballard JE, Boileau RA. The effects of long-term stimulant medication on the growth and body composition of hyperactive children. Psychopharmacol Bull 1976;12:13-15.

20 McNutt BA, Boileau RA, Cohen MN. The effects of long-term stimulant medication on the growth and body composition of hyperactive children. Psychopharmacol Bull 1977;13(2):36-8.

21 Spencer TJ, Biederman J, Harding M, et al. Growth deficits in ADHD children revisited: evidence for disorder-associated growth delays? J Am Acad Child Adolesc Psychiatry 1996;35:1460-9.

22 Spencer T, Biederman J, Wilens T. Growth deficits in children with attention deficit hyperactivity disorder. Pediatrics 1998;102:501-6.

23 Biederman J, Faraone SV, Monuteaux MC, et al. Growth deficits and attention-deficit/hyperactivity disorder revisited: impact of gender, development and treatment. Pediatrics 2003;111:1010-16.

24 Millichap JG, Millichap M. Growth of hyperactive children. N Engl J Med 1975;292:1300.

25 Vincent J, Varley CK, Leger P. Effects of methylphenidate on early adolescent growth. Am J Psychiatry 1990;147:501-2.

26 Klein RG, Landa B, Mattes JA, et al. Methylphenidate and growth in hyperactive children. A controlled withdrawal study. Arch Gen Psychiatry 1988;45:1127-30

27 Vaughan VC. Growth and development. In: Nelson WE, Vaughan VC, McKay RJ, eds. Textbook of paediatrics. Philadelphia, London, Toronto: W.B. Saunders Company, 1969:15-57.

28 Vaughan VC. Developmental paediatrics. In: Behrman RE, Vaughan VC, eds. Nelson: textbook of pediatrics. Philadelphia, London, Toronto, Mexico City, Rio de Janeiro, Sydney, Tokyo: W.B. Saunders Company, 1983:10-135.

29 Beck L, Langford WS, Mackay M, et al. Childhood chemotherapy and later drug abuse and growth curve: a follow up study of 30 adolescents. Am J Psychiatry 1972;132:436-8.

30 Hechtman L, Weiss G, Perlman T. Young adult outcome of hyperactive children who received long-term stimulant treatment. J Am Acad Child Psychiatry 1984;23:261-9.

31 Klein RG, Mannuzza S. Hyperactive boys almost grown up. III. Methylphenidate effects on ultimate height. Arch Gen Psychiatry 1988;45: 1131-4

32 Kramer JR, Loney J, Ponto LB, et al. Predictors of adult height and weight in boys treated with methylphenidate for childhood behavior problems. J Am Acad Child Adolesc Psychiatry 2000;39:517-24.

33 Oettinger L, Gauch RR, Majovski LV. Maturity and growth in children with MBD. In: Millichap JG, ed. Learning disabilities and related disorders. Chicago, IL: Year Book Medical Publishers, 1977:141-9.

34 Loney J, Whaley-Klahn MA, Ponto LB, et al. Predictors of adolescent height and weight in hyperkinetic boys treated with methylphenidate. Psychopharmacol Bull 1981;17:132-4.

35 Safer DJ, Allen RP, Barr E. Depression of growth in hyperactive children on stimulant drugs. N Engl J Med 1972;287:217-20.

36 Previously unpublished analysis of data from the same study as reference 15. 